\title{
Variation in the prices of oncology medicines across Europe and the implications for the future
}

Brian Godman, BSc, $\mathrm{PhD}^{1,2,3^{*}}$, Steven Simoens, MSc, $\mathrm{PhD}^{4}$, Amanj Kurdi, BSc, $\mathrm{PhD}^{1,5}$, Gisbert Selke ${ }^{6}$, John Yfantopoulos ${ }^{7}$, Andrew Hill, $\mathrm{PhD}^{8}$, Jolanta Gulbinovič, MD, $\mathrm{PhD}^{9}$, Antony P Martin, MA, $\mathrm{PhD}^{10,11}$, Angela Timoney, BPharm, PhD ${ }^{1,12}$, Dzintars Gotham, MBBS ${ }^{13}$, Janet Wale, $\mathrm{PhD}^{14}$, Tomasz Bochenek, PhD ${ }^{15}$, Iva Selke Krulichová ${ }^{16}$, Eleonora Allocati, MSc ${ }^{17}$, Iris Hoxha ${ }^{18}$, Admir Malaj ${ }^{19}$, Christian Hierländer ${ }^{20}$, Anna Nachtnebel ${ }^{20}$, Wouter Hamelinck ${ }^{21}$, Zornitza Mitkova ${ }^{22}$, Guenka Petrova, $\mathrm{PhD}^{22}$, Ott Laius, $\mathrm{PhD}^{23}$, Catherine Sermet, MD, $\mathrm{PhD}^{24}$, Irene Langner ${ }^{6}$, Roberta Joppi ${ }^{25}$, Arianit Jakupi ${ }^{26}$, Elita Poplavska, $\mathrm{PhD}^{27}$, leva Greiciute-Kuprijanov ${ }^{28}$, Patricia Vella Bonanno, $\mathrm{PhD}^{1}$, JF (Hans) Piepenbrink ${ }^{29}$, Vincent de Valk ${ }^{29}$, Robert Plisko ${ }^{30}$, Magdalene Wladysiuk ${ }^{30}$, Vanda MarkovićPeković, PhD ${ }^{31}$, lleana Mardare, $\mathrm{PhD}^{32}$, Tanja Novakovic ${ }^{33}$, Mark Parker ${ }^{33}$, Jurij Fürst ${ }^{34}$, Dominik Tomek, PharmD, MSc, PhD ${ }^{35}$, Katarina Banasova ${ }^{36}$, Mercè Obach Cortadellas ${ }^{37}$, Corrine Zara ${ }^{37}$, Caridad Pontes ${ }^{37,38}$, Maria Juhasz-Haverinen ${ }^{39}$, Peter Skiold ${ }^{40}$, Stuart McTaggart ${ }^{41}$, Durhane WongRieger ${ }^{42}$, Stephen Campbell, $\mathrm{PhD}^{43,44}$, Ruaraidh Hill, $\mathrm{PhD}^{45}$

${ }^{1}$ Strathclyde Institute of Pharmacy and Biomedical Sciences, University of Strathclyde, Glasgow G4 ORE, United Kingdom. Email: Brian.godman@strath.ac.uk; amanj.baker@strath.ac.uk; patricia.vellabonanno@strath.ac.uk

${ }^{2}$ Division of Clinical Pharmacology, Karolinska Institute, Karolinska University Hospital Huddinge, SE141 86, Stockholm, Sweden. Email: Brian.Godman@ki.se.

${ }^{3}$ School of Pharmacy, Sefako Makgatho Health Sciences University, Pretoria, Gauteng, South Africa ${ }^{4} \mathrm{KU}$ Leuven Department of Pharmaceutical and Pharmacological Sciences, Leuven, Belgium. Email: steven.simoens@kuleuven.be

${ }^{5}$ Department of pharmacology, College of Pharmacy, Hawler Medical University, Erbil, Iraq

${ }^{6}$ Wissenschaftliches Institut der AOK (WidO), Rosenthaler Straße 31, 10178 Berlin, Germany. Email: Gisbert.Selke@wido.bv.aok.de; irene.langner@wido.bv.aok.de

${ }^{7}$ School of Economics and Political Science, University of Athens, Athens. Email: yfantopoulos@gmail.com

${ }^{8}$ Institute of Translational Medicine, University of Liverpool, UK. Email: microhaart@aol.com

${ }^{9}$ Department of Pathology, Forensic Medicine and Pharmacology, Institute of Biomedical Sciences, Faculty of Medicine, Vilnius University, Vilnius, Lithuania. Email: jolanta.gulbinovic@gmail.com

${ }^{10}$ Wolfson Centre for Personalised Medicine, University of Liverpool, Liverpool, UK, Liverpool, UK.

Email: a.p.martin@liverpool.ac.uk

${ }^{11} \mathrm{HCD}$ Economics, The Innovation Centre, Daresbury, WA4 4FS, UK. Email:

antony.martin@hcdeconomics.com

${ }^{12} \mathrm{NHS}$ Lothian, Edinburgh, UK. Email: angela.timoney@nhslothian.scot.nhs.uk

${ }^{13}$ Independent researcher, London, UK. Email: dzintarsgotham@gmail.com

${ }^{14}$ Independent consumer advocate, 11a Lydia Street Brunswick, Victoria 3056 Australia. Email: socrates111@bigpond.com

${ }^{15}$ Department of Drug Management, Faculty of Health Sciences, Jagiellonian University Medical College, Krakow, Poland. Email: mxbochen@cyf-kr.edu.pl

${ }^{16}$ Department of Medical Biophysics, Faculty of Medicine in Hradec Králové, Charles University,

Simkova 870, 50003 Hradec Králové, Czech Republic. Email: krulich@lfhk.cuni.cz

${ }^{17}$ Istituto di Ricerche Farmacologiche 'Mario Negri' IRCCS, Milan, Italy. Email:

eleonora.allocati@marionegri.it

${ }^{18}$ Department of Pharmacy, Faculty of Medicine, University of Medicine, Tirana, Albania. Email: iris.hoxha@umed.edu.al

19University of Medicine, Tirana, Albania. Email: admir.malai@yahoo.it

${ }^{20}$ Dachverband der Sozialversicherungsträger, Kundmanngasse 21, AT-1030, Vienna, Austria. Email: christian.hierlaender@sozialversicherung.at; Anna.Nachtnebel@sozialversicherung.at

${ }^{21}$ Statistics Department, APB,Rue Archimède 11, 1000 Bruxelles, Belgium. Email:

wouter.hamelinck@apb.be

${ }^{22}$ Faculty of Pharmacy, Department of Social Pharmacy and Pharmacoeconomics, Medical University of Sofia, Sofia, Bulgaria. Email: guenka.petrova@gmail.com; sppmitkova@mail.bg

${ }^{23}$ State Agency of Medicines, Nooruse 1, 50411 Tartu, Estonia. Email: Ott.Laius@ravimiamet.ee

${ }^{24}$ IRDES, 117 bis rue Manin, 75019 Paris, France. Email: sermet@irdes.fr

${ }^{25}$ Pharmaceutical Drug Department, Azienda Sanitaria Locale of Verona, Verona, Italy;

Email: roberta.joppi@ aulss9.veneto.it

${ }^{26}$ UBT - Higher Education Institut , Prishtina, Kosovo. Email: arianiti@gmail.com 
${ }^{27}$ Medicines Marketing Authorisation Department, State Agency of Medicine, Riga, Latvia. Email: poplavska.elita@gmail.com

${ }^{28}$ Department of Pharmacy, Ministry of Health of the Republic of Lithuania, Vilnius, Lithuania, Email: leva.Greiciute-Kuprijanov@sam.It

${ }^{29}$ National Health Care Institute (ZIN), Eekholt 4, NL-1112 XH Diemen, Netherlands. Email: VValk@zinl.nl; HPiepenbrink@zinl.nl

30HTA Consulting, Starowiślna Str. 17/3, 31-038 Cracow, Poland. Email: m.wladysiuk@hta.pl; r.plisko@hta.pl

${ }^{31}$ University of Banja Luka, Faculty of Medicine, Department of Social Pharmacy, Banja Luka, Republic of Srpska, Bosnia and Herzegovina. Email: vanda.markovic-pekovic@med.unibl.org ${ }^{32}$ Faculty of Medicine, Public Health and Management Department, "Carol Davila" University of Medicine and Pharmacy Bucharest, 050463 Bucharest, Romania. Email: ileana.mardare@umfcd.ro 33ZEM Solutions, Mosorska 9, 11000 Belgrade, Serbia. Emails: tanja@zem-solutions.com; mark@zem-solutions.com

${ }^{34}$ Health Insurance Institute, Miklosiceva 24, SI-1507 Ljubljana, Slovenia. Email: Jurij.Furst@zzzs.si

${ }^{35}$ Faculty of Medicine, Slovak Medical University in Bratislava, Bratislava, Slovakia. Email: tdmia@slovanet.sk

${ }^{36}$ Slovak society for Pharmacoeconomics, Bratislava, Slovakia. Email: katarina.banasova@gmail.com

${ }^{37}$ Drug Area, Catalan Health Service, Catalan Health Service, Travessera de les Corts 131, Edifici

Olimpia, 08028 Barcelona, Spain. Email: czara@catsalut.cat; mobach@catsalut.cat; cpontes@catsalut.cat

${ }^{38}$ Department of Pharmacology, Therapeutics and Toxicology, Universitat Autònoma de Barcelona,

Barcelona, Spain

${ }^{39}$ Stockholm County Council, Stockholm, Sweden. Email: maria.juhasz-haverinen@sll.se

${ }^{40}$ TLV (Dental and Pharmaceutical Benefits Agency), Fleminggatan 18, 104 22, Stockholm, Sweden.

Email: Peter.Skiold@tlv.se

${ }^{41} \mathrm{NHS}$ National Services Scotland, Gyle Square, 1 South Gyle Crescent, Edinburgh, UK. Email:

stuart.mctaggart@nhs.net

${ }^{42}$ Canadian Organization for Rare Disorders, 151 Bloor Street West, Suite 600, Toronto, Ontario,

Canada. Email: durhane@sympatico.ca

${ }^{43}$ Centre for Primary Care, Division of Population Health, Health Services Research and Primary

Care, University of Manchester, Manchester, M13 9PL, UK. Email:

stephen.campbell@manchester.ac.uk

${ }^{44} \mathrm{NIHR}$ Greater Manchester Patient Safety Translational Research Centre, School of Health

Sciences, University of Manchester, Manchester, UK

${ }^{45}$ Evidence Synthesis, Health Services Research, University of Liverpool, Liverpool, UK. Email:

rahill@liverpool.ac.uk

*Author for correspondence: Strathclyde Institute of Pharmacy and Biomedical Sciences, University of Strathclyde, Glasgow G4 ORE, United Kingdom. Email: Brian.Godman@strath.ac.uk. Telephone: 0141548 3825. Fax: 01415522562

Key words: Cancer, pricing, cross-national, Europe, health policy, generics

(Accepted for publication GABI Journal)

\footnotetext{
Abstract

Introduction/ Objectives: There are increasing concerns among health authorities regarding the sustainability of healthcare systems with growing expenditure on medicines including new high-priced oncology medicines. Medicine prices among European countries may be adversely affected by their population size and economic power to negotiate. There are also concerns that prices of patented medicines do not change once the prices of medicines used for negotiations substantially change. This needs to be investigated as part of the implications of low-cost generic oncology medicines. Methodology: Analysing principally reimbursed prices of patented oral oncology medicines (imatinib, erlotinib and fludarabine) between 2013 and 2017 across Europe and exploring correlations between GDP, population size, and prices. Comparing the findings with previous research regarding prices of oral generic oncology medicines. Results: The prices of imatinib, erlotinib and fludarabine did vary among European countries but showed limited price erosion over time in the absence of generics. There appeared to be no correlation between population size and prices. However, higher prices were seen among countries with higher GDP per capita which is a concern for lower income countries referencing these. Discussion and Conclusion: It is likely that the limited price erosion for patented oncology medicines will change across
} 
Europe with increased scrutiny over their prices and value as more medicines used for pricing decisions lose their patents combined with growing pressures on the oncology drug budget. In addition, discussions will continue regarding fair pricing for new oncology medicines and other approaches given ever rising prices with research showing substantial price reductions for oral oncology medicines (up to $-97.8 \%$ for imatinib) once generics become available. We are also seeing appreciable price reductions for biosimilars further increasing the likelihood of these developments.

\section{Introduction}

Expenditure on medicines has risen across countries in recent years, driven principally by increased prescribing volumes and increasing prices for new medicines especially those for oncology and orphan diseases (1-4). Prices of new oncology medicines have risen by ten-fold or more during the last decade (5-8), with prices per life year gained for new oncology medicines rising four-fold during the past twenty years after adjusting for inflation $(6,9)$. As a result, expenditure on oncology medicines now dominate pharmaceutical expenditure in high income countries, which will continue with over 500 companies actively pursuing new oncology medicines in over 600 indications $(10,11)$ with envisaged high price expectations $(12,13)$. Overall, global expenditure on oncology medicines is estimated to reach $\$ 237$ billion by 2024 (14), with the cost of cancer care already accounting for up to $30 \%$ of total hospital expenditure across Europe and rising $(15,16)$.

This growth in expenditure on oncology medicines is putting considerable strain on European healthcare systems with their universal access unless this is addressed $(4,13,17,18)$. This is leading to calls that high prices for new oncology medicines need to be increasingly linked to a minimum improvement in clinical benefit including a minimum of three to six months additional survival versus existing regimens with even three months seen as a marginal clinical benefit (19-23). This is because European countries have funded new cancer medicines at high prices in recent years despite limited health gain and formal pricing and reimbursement processes among European them (23-26), exacerbated by the emotive nature of the disease area (12). These concerns are also leading to calls for alternative pricing and funding approaches towards new oncology medicines in Europe and wider, which include fair pricing models (25, 27-31). Fair pricing models necessarily include greater transparency in how prices are set, which is a continuing goal of the World Health Organisation (WHO) to improve access to new medicines for all patients including those for cancer $(32,33)$. Calls for increased transparency have also grown in recent years with greater knowledge of the low cost of goods (cost of ingredients and manufacturing) of some new cancer medicines as well as appreciable discounting by pharmaceutical companies for their biological medicines when faced with biosimilar competition $(27,34,35)$. The situation is even more critical in the USA with continuing price rises for existing patented oncology medicines as well as a continuing increase in the requested price of new cancer medicines as a result of no formal pricing and reimbursement processes, leading to oncologists requesting moderation in the prices of new oncology medicines (36). However, this has failed to currently materialise reflected by estimations of US $\$ 39.5$ billion for the net expenditure on 46 new oncology medicines approved in 2018 in the USA, 17 for novel drugs and 29 new indications, if all eligible patients received them (37). Potential expenditure on oncology medicines would be even greater in recent years as this figure doe not include expenditure on the other oncology medicines (37).

Once prices for medicines are established in Europe, there appears to be limited price erosion until multiple sources become available unlike the situation in the USA $(38,39)$. There also appears to be limited differences among European countries regarding prices for patented biological oncology medicines, with Vogler et al (2017) only demonstrating a 13\% difference among 16 European countries for prices including bevacizumab and ipilimumab. However, they found greater differences for lower priced medicines (40). Similarly, Vokinger et al. (2020) observed limited differences in the monthly treatment costs for new oncology medicines among European countries; however, costs of medicines in the USA were a median of 2.31 times higher than those seen in Europe reflecting the current lack of pricing controls in the USA $(39,41)$. The situation in Europe may reflect extensive external referencing pricing for new medicines $(25,42)$, although we have seen considerable differences in the pricing of multiple sourced oncology medicines among European countries (43).

Consequently, we wanted to build on the recent findings of Vogler et al (2017), Vogler et al (2019) and Vokinger et al. (2020) to review the prices of oral cancer medicines over time among European countries to provide future direction to health authorities $(38,40,41)$. This also involves assessing the 
potential influence of Gross Domestic Product (GDP) and population sizes on the reimbursed prices of patented medicines across Europe in view of concerns that countries with smaller populations and less economic power could suffer in negotiations with resultant higher prices acknowledging though extensive external reference pricing across Europe $(41,42)$. These concerns were the trigger for cross country consortia to develop across Europe to enhance countries' negotiating powera for new premium priced medicines, which currently include Beneluxa, Valleta and the Nordic consortium (33, 44-46). We are aware though from our earlier findings that the prices of oral generic cancer medicines across Europe were not dependant on population sizes or the economic status of countries; however, they did fall over time with some appreciable reductions observed (43). This though may be different for patent protected oral cancer medicines. We believe the combined findings should stimulate debate about future reimbursement and pricing of existing patented oncology medicines as more oncology medicines lose their patents potentially appreciably altering their cost-effectiveness and overall value. In addition, we believe the findings can further stimulate debates regarding possible new approaches to the pricing of new oncology medicines in Europe including fair pricing models given the unsustainability of the current system. This builds on current initiatives from the WHO, European Commission and European insurers to push for greater transparency in pricing negotiations $(18,22$, 28, 33).

We have chosen to concentrate on Europe for this combined research in view of their goals of equitable and universal healthcare, growing concerns with expenditure on new oncology medicines and those for orphan diseases, and multiple ongoing activities to improve the efficiency and quality of prescribing for both new and established medicines $(20,21,25,47-51)$. European countries also have formal pricing and reimbursement processes with input from health technology agencies and others, with processes the jurisdiction of each Member State, to review and refine future approaches $(25,39$, 52). This contrasts with the USA with currently no formal pricing and reimbursement systems, with concerns that the system is not working leading to spending on medicines currently accounting for over $40 \%$ of global pharmaceutical spend despite the USA only having $4.5 \%$ of the world's population (39). In addition, increasing calls from US groups for the government to consider approaches and systems from among European and other countries going forward given the unsustainability of their current system (39). We have adopted a payer perspective for our research as they are key personnel involved in funding and reimbursement decisions for new oncology medicines across Europe. As a result, we used health authority databases for the combined research as they are regularly audited and reflect the prices paid by health authorities for their medicines with or without Value Added Tax (VAT) depending on the country $(43,53-55)$.

\section{Methodology}

The methodology has been extensively discussed in the first paper of Godman et al. (43). The European countries involved included: Albania, Austria, Belgium, B \& H (Republic of Srpska), Bulgaria, Cyprus, Estonia, France, Germany, Greece, Italy, Kosovo, Latvia, Lithuania, Malta, Netherlands, Norway, Poland, Romania, Serbia, Slovenia, Slovakia, Spain (represented by pricing data from Catalonia with list prices similar across Spain), Sweden, and the United Kingdom (UK), which is represented by Scotland with tariff prices consistent across the UK. These countries were chosen since they not only represent a wide range of geographies, populations and GDP, but were also able to provide robust data from their administrative databases. Pricing data from health authorities is seen as reliable and robust since, as mentioned, their systems are regularly audited (43, 56). We have also used this approach in previous multiple cross-national publications when assessing utilisation and expenditure patterns for different medicines and disease areas across Europe $(43,53-$ $55,57-59)$.

This paper will principally concentrate on reimbursed prices for imatinib (L01XE01), erlotinib (L01XE03) and fludarabine (L01BB05) (60) among Western European countries since there were no generics available for these oral oncology medicines in 2015 for imatinib or 2017 for erlotinib and fludarabine, and external reference pricing is used to a lesser extent in these countries $(42,43,53)$. The later availability of generics for these oral cancer medicines among Western European countries enables a longer time period to monitor any price erosion. This builds on the earlier findings of Godman et al. (43), which involved assessing reimbursed prices for generic busulfan (L01AB01), capecitabine (L01BC06), chlorambucil (L01AA02), cyclophosphamide (L01AA01), flutamide (L02BB01), imatinib (L01XE01), melphalan (L01AA03), and temozolomide (L01AX03) over time across Europe (43). 
Reimbursed prices were used where possible since, as mentioned, the perspective of this paper is that of European health authorities. However, in a minority of countries procured and total prices were used, e.g. Kosovo. This is because it was impossible to break the prices down into individual components. Total prices include pharmacy remuneration and any patient co-payments. In some countries, VAT was also included in the price depending on the situation in the country. Again, it was difficult to deduct this proportion from the prices provided. Documented prices could also include any discounted prices arising from managed entry agreements (MEAs) sometimes referred to as risk sharing arrangements $(51,61)$. However, these were rare for individual oncology medicines in Europe before the recent rapid rises in requested prices of new oncology medicines to enhance their affordability and subsequent reimbursement (61-64). We are aware in some countries that reimbursed prices were listed but the medicines are typically dispensed in hospitals where further confidential discounts are provided, e.g. Norway and Italy, which are typically confidential.

In general, reimbursed prices were collected between 2013 and 2017 based on tablet strength. Tablet strength was chosen for comparative purposes as opposed to defined daily doses that we have used in previous cross-national research projects $(53-55,57,58)$ as generally there are no defined daily doses (DDDs) for oral cancer medicines (60). The actual tablet strength chosen reflects the most used strength in a number of European countries for patients with cancer.

Initially prices were documented in the country's currency if not listed in Euros. Subsequently, where relevant, prices were converted to Euros for comparison purposes based on current exchange rates and validated by the co-authors to enhance the robustness of the findings $(43,65-72)$. Prices were subsequently converted to US\$ based on mid-year European Central Bank exchange rates for comparison purposes with GDP per capita based principally on OECD data for 2015 and 2017 (7375). However, prices were retained in Euros when calculating any price erosion of the patented oral oncology medicines over time. Euros were also used for comparing prices of oral generic cancer medicines as one of the principal aims of this paper was to compare prices across countries as well as any price reductions achieved (43).

The OECD was the principal source for data on GDP per capita in US\$ in 2015 and 2017 (current prices and purchasing price parity) (73). This data was supplemented with additional data, e.g. Albania, Cyprus - 2018, Kosovo, Malta, Romania, and Serbia, where necessary (76-79). Data from the OECD was also principally used for population sizes in 2015 and 2017 for consistency; however, data from other sources was also used where pertinent (80-86). Country abbreviations were based on the International Organization for Standardization abbreviations (Table 1A in the Appendix) (87).

Differences in country prices were visualised as violin plots to enhance interpretation of the data. Nonparametric Spearman's rank tests were used to assess any correlation between prices of these three originator medicines and country's population size as well as their GDP per capita. The correlations were presented as Spearman's rank correlation coefficient which ranges from -1 (perfect negative correlation) to +1 (perfect positive correlation). A p-value less than 0.05 was considered statistically significant. The correlations were also visually presented using scatter plots. Calculations were performed using the software R 3.6.1 (88).

No ethical approval was needed as we were dealing with aggregated anonymised data in accordance with previous studies undertaken by the co-authors using administrative databases $(43,47,54,57$, 89). The definition of terms used such as external reference pricing, MEAs, and value-based pricing, follow those in Vogler et al (2019) for reforms and initiatives introduced across Europe (25).

\section{Results}

\subsection{Prices of oral generic cancer medicines across Europe}

The study of Godman et al (2019) showed that there were variable approaches to the pricing of generic oral oncology medicines across Europe, similar to the situation generally for the pricing of generic medicines $(43,50,53,90,91)$. The different approaches can be consolidated into three categories (43), and include:

- $\quad$ prescriptive pricing policies (price regulated market), i.e. policies with established percentage reductions for successive generics 
- market forces (free market) where there is typically free pricing for generics with market forces helping to drive down prices

- mixed approach (combination) which incorporates prescriptive approaches, market forces and other mechanisms including external reference pricing among selected European countries with external reference pricing common across Europe

The differences in the adopted approaches among the various European countries resulted in appreciable differences in subsequent reimbursed prices for oral generic oncology medicines across Europe as well as appreciable differences in the price reductions seen in a number of European countries versus pre-patent loss prices (Box 1 ).

Box 1 - Reimbursed prices for oral generic oncology tablets across Europe in 2017 and price reductions over time (43).

A) Reimbursed prices in 2017

- Prices per $500 \mathrm{mg}$ capecitabine generic tablets ranged from $€ 0.21$ in Poland and $€ 0.31$ in Malta up to $€ 2.46$ in the United Kingdom (UK).

- Prices for $250 \mathrm{mg}$ flutamide generic tablets ranged from $€ 0.16$ in Poland and $€ 0.23$ in Greece up to $€ 1.43$ in the UK.

- Prices for temozolomide 20mg generic tablets ranged from $€ 0.86$ in Poland and $€ 2.28$ in Romania up to $€ 17.64$ in France.

- Prices of temozolomide 250mg generic tablets ranged from €9.47 in Poland and €25.87 in Sweden up to $€ 220.52$ in France.

\section{B) Price reductions}

- Reimbursed prices of generic capecitabine among European countries in 2017 were up to $93.1 \%$ below 2013 originator prices. These varied from a reduction of only $7.1 \%$ in one European country up to an ultimate price reduction of $93.1 \%$ for the multiple sourced medicine versus pre-patent loss prices.

- Reimbursed prices of generic imatinib were up to $97.8 \%$ below originator 2013 prices. These varied from a limited reduction of only $3.4 \%$ up to an appreciable reduction of $97.8 \%$ versus pre-patent loss prices.

- Reimbursed prices of generic temozolomide $20 \mathrm{mg}$ were up to $80.7 \%$ below 2013 originator prices. These again varied considerably depending when generic temozolomide first became available. In the case of $20 \mathrm{mg}$ temozolomide, these varied from no reduction up to a maximum reduction of $80.7 \%$; the maximum reduction for $250 \mathrm{mg}$ was similar at $79.6 \%$

Reimbursed prices were not indication specific, i.e. there were no differential prices once the first indication had lost its patent. In addition, the prices seen for the oral generic oncology medicines in 2017 did not appear to be affected by the population size of a country or typically by its wealth (Central and Eastern Europe versus Western European countries) compared to previous beliefs (43, 92). There were also no concerns with substitution with oral generic oncology medicines (43). This is encouraging as there have been concerns with substitution of some medicines including lithium, modified release calcium antagonists and medicines for epilepsy in view of possible issues with effectiveness and side-effects with different formulations, which limits the extent of savings ince generics become available (93).

\subsection{Prices of oral originator cancer medicines across Europe}

\subsubsection{Imatinib}

Table 1 documents the prices for originator 400mg imatinib among Western European countries in 2015 before generic availability, with Figure 1 depicting the spread of prices across the studied countries. This was because generic imatinib was already available in CEE countries before this, e.g. Albania, Estonia, Latvia, Lithuania, Romania, Serbia and Slovakia in 2013 or before, and in Poland and Slovenia in 2014 (43), and originator prices typically fall in these countries once generics become availabe $(43,50,90)$. 
Table 1 - Price per tablet (US\$) for originator imatinib 400mg among 11 European countries in 2015 where no generic imatinib was available

\begin{tabular}{|l|c|c|c|c|}
\hline Country & Price (US\$) & Population $(\mathbf{m n})$ & $\begin{array}{c}\text { GDP per Capita } \\
\text { (US\$) }\end{array}$ & VAT Included \\
\hline Cyprus & 90.13 & 1.17 & 23248 & Yes \\
\hline Norway & 88.81 & 5.17 & 60492 & Yes \\
\hline Austria & 94.21 & 8.59 & 49954 & No \\
\hline Sweden & 94.25 & 9.75 & 48437 & No \\
\hline Greece & 78.60 & 10.86 & 26902 & Yes \\
\hline Belgium & 92.17 & 11.24 & 45739 & No \\
\hline Netherlands & 92.02 & 16.90 & 50302 & Yes \\
\hline Spain & 87.65 & 46.45 & 35054 & No \\
\hline UK & 86.77 & 64.85 & 42055 & Yes \\
\hline France & 84.00 & 66.46 & 40841 & Yes \\
\hline Germany & 124.68 & 81.20 & 47979 & 45739 \\
\hline Median & 90.13 & 11.24 & & \\
\hline
\end{tabular}

All values for 2015. Conversion rate: $€ 1=$ US $\$ 1.1100$ (mid 2015). VAT included where social security organisations are subject to VAT. Countries in order of population size. Abbreviations: $m n=$ million; VAT = value added tax

Figure 1 - Violin plots of the originator price distributions for the three substances studied, in the respective years (2015 and 2017 )

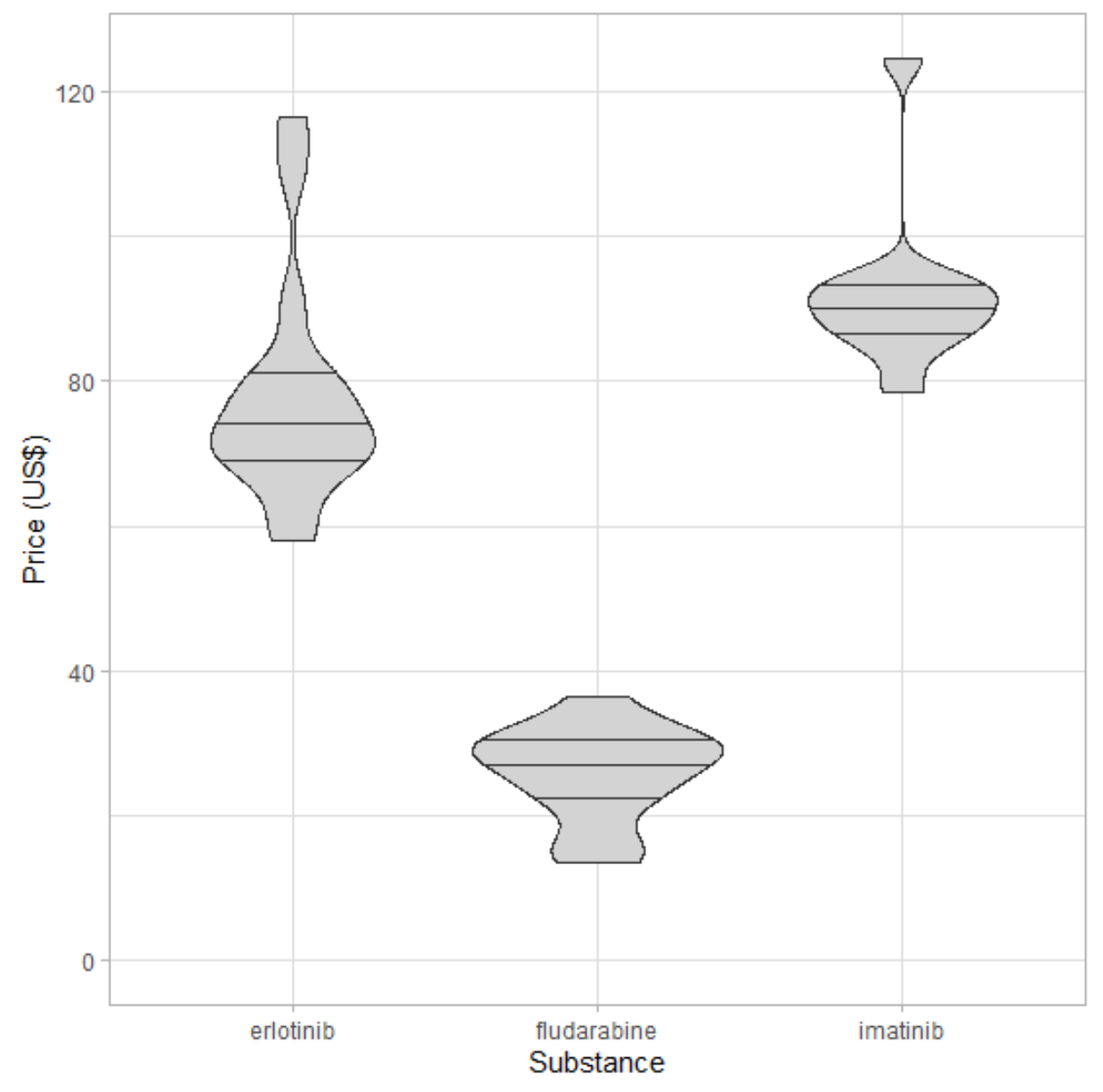

Horizontal lines within the violins mark the quartiles. 
Whilst the minimum price of imatinib was $12.8 \%$ below and the maximum price $4.6 \%$ above (excluding the outlier Germany at $+38.3 \%$ ) the median price (US $\$ 90.13$ ), the results of the Spearman's rank test indicated no correlation $(r=-0.100 ; p=0.776)$ between the price of imatinib and the countries' population size (Appendix Figure $1 \mathrm{~A}$ ). However, there was a moderate positive correlation approaching significance $(r=+0.527 ; p=0.100)$ between imatinib prices and GDP per capita (Figure 2).

Figure 2 - Scatter plot of originator imatinib prices against GDP per capita for 11 European countries where no generic imatinib existed in 2015

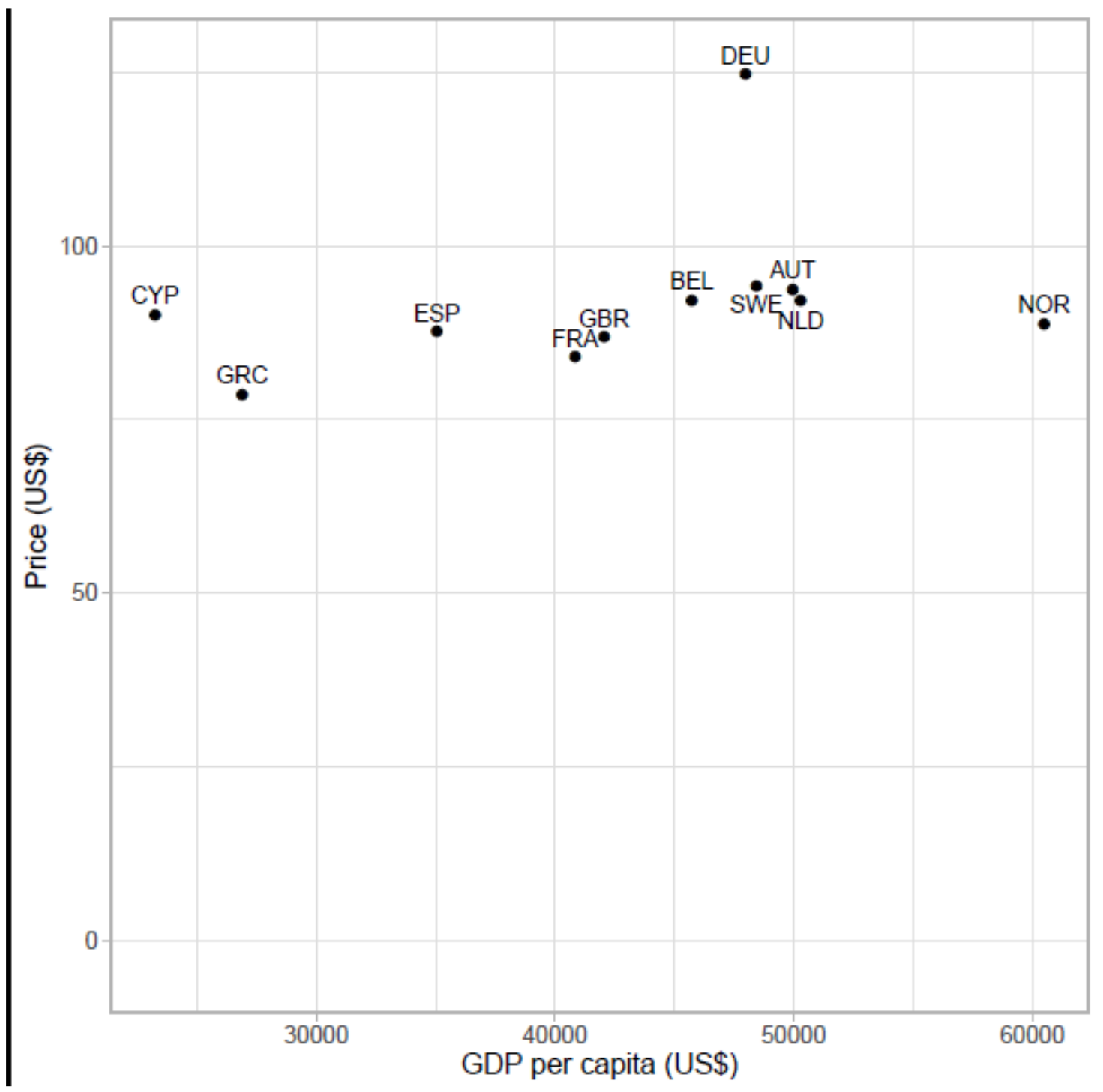

\subsubsection{Erlotinib}

Generic erlotinib (150mg) was not available among the studied Western European countries as well as a number of CEE countries in 2017 (43). Consequently, we were able to survey prices among 16 European countries. Whilst prices varied from $20.9 \%$ below to $23.2 \%$ above (disregarding the outliers Germany and Italy at $49.0 \%$ and $58.8 \%$ respectively) the median price (73.44 US\$; Table 2; Figure 1), we found no significant correlation $(r=0.303 ; p=0.253)$ between the prices of erlotinib and countries' population size (Figure 2A in the Appendix). On the other hand, there was a significant moderate positive correlation ( $r=0.532 ; p=0.036$ ) between erlotinib prices and GDP per capita (Figure 3 ). 
Table 2 - Price per tablet (US\$) for originator erlotinib 150mg among 16 European countries in 2017 where no generic erlotinib was available

\begin{tabular}{|c|c|c|c|c|}
\hline Country & Price (US\$) & Population (mn) & GDP per Capita (US\$) & VAT Included \\
\hline Malta & 90.50 & 0.44 & 27241 & No \\
\hline Kosovo & 69.73 & 1.83 & 3948 & No \\
\hline Slovenia & 70.77 & 2.07 & 36163 & No \\
\hline Albania & 58.08 & 2.87 & 4533 & No \\
\hline Norway & 79.72 & 5.26 & 62182 & Yes \\
\hline Slovakia & 72.41 & 5.44 & 32376 & Yes \\
\hline Serbia & 60.92 & 7.10 & 6284 & Yes \\
\hline Austria & 69.99 & 8.77 & 53895 & No \\
\hline Sweden & 76.72 & 10.00 & 51405 & No \\
\hline Greece & 68.83 & 10.77 & 28580 & Yes \\
\hline Netherlands & 80.96 & 17.08 & 54504 & No \\
\hline Spain & 74.47 & 46.53 & 39087 & Yes \\
\hline Italy & 116.62 & 60.59 & 40981 & Yes \\
\hline UK & 69.68 & 65.84 & 44909 & No \\
\hline France & 78.51 & 66.80 & 44125 & Yes \\
\hline Germany & 109.44 & 82.52 & 52574 & Yes \\
\hline Median & 73.44 & 9.38 & 40034 & \\
\hline
\end{tabular}

All values for 2017. Conversion rate: $€ 1=$ US $\$ 1.1369$ (mid 2017). VAT included where social security organisations are subject to VAT. Countries in order of population size. Abbreviations: $\mathrm{mn}=$ million; VAT = value added tax

Figure 3 - Scatter plot of originator erlotinib prices against GDP per capita for 16 European countries where no generic erlotinib existed in 2017

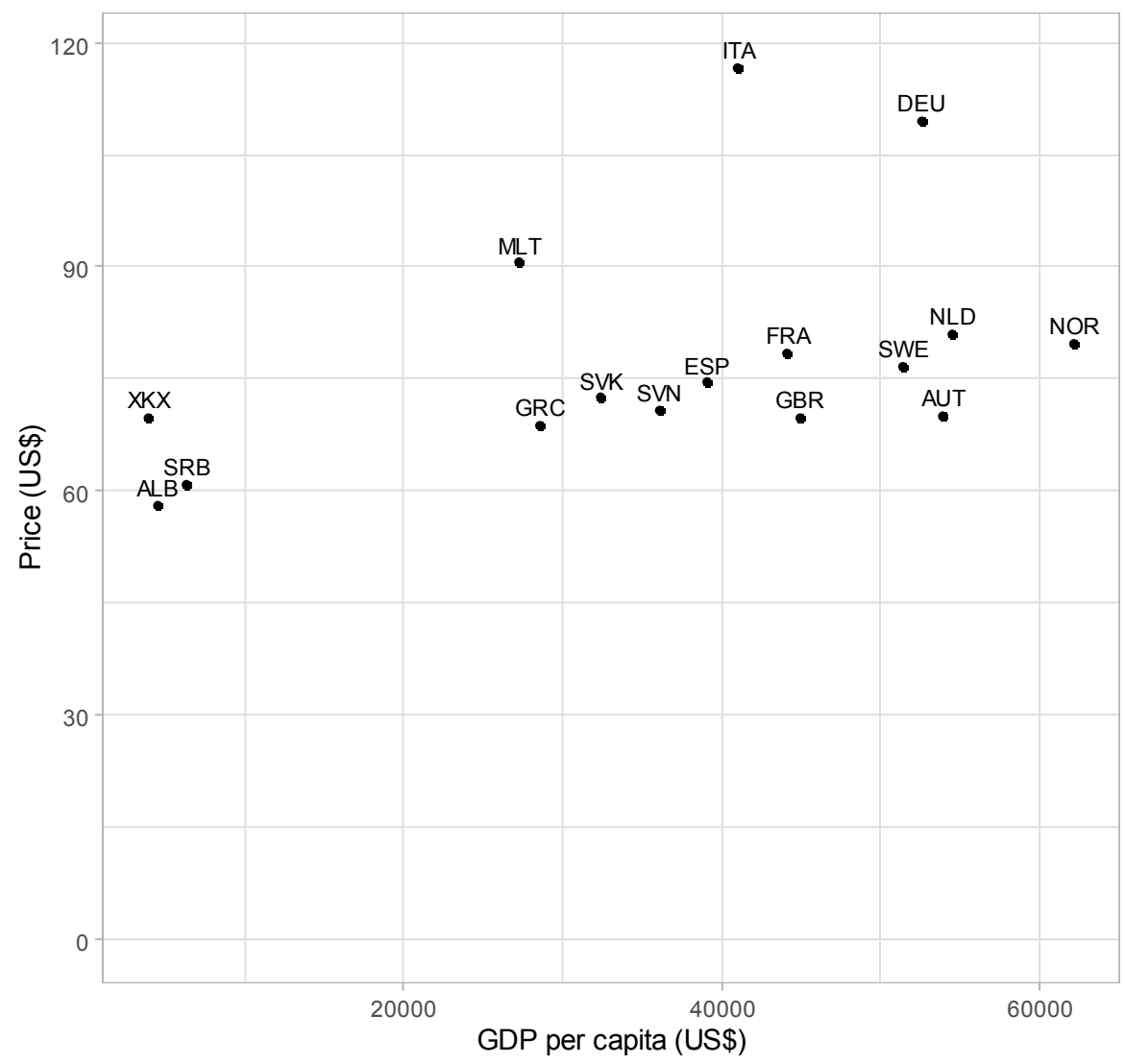


There were limited differences in prices for originator erlotinib over time among the various Western European countries (Table 2). However once multiple versions become available, we would expect prices to fall rapidly as seen with generic erlotinib in the Republic of Srpska in 2017 (26.9\% below 2013 originator prices), Bulgaria (34.3\% below), Romania (45.7\% below) and Lithuania (54.4\% below 2013 originator prices) as well as with other oral cancer medicines in Europe following generic availability (43).

\subsubsection{Fludarabine}

Generic fludarabine was not available among Western European countries and a number of CEE countries in 2017. As a result, we were able to include prices from 16 European countries in the analysis.

Documented prices (Table 3; Figure 1) ranged from $53 \%$ below to $29 \%$ above the median $(28.09$ US\$). Again, we found no correlation $(r=0.035 ; p=0.900)$ between the price of fludarabine and the countries' population size (Figure 3A). However, a significant moderate positive correlation $(r=0.515$; $\mathrm{p}=0.044$ ) was observed between fludarabine prices and GDP per capita (Figure 4).

Table 3 - Price per tablet (US $\$$ ) for originator fludarabine 10mg in 2017 among 16 European countries in 2017 where no generic fludarabine was available

\begin{tabular}{|l|c|c|c|c|}
\hline Country & Price (US\$) & Population (mn) & GDP per Capita (US\$) & VAT Included \\
\hline Malta & 31.01 & 0.44 & 27241 & No \\
\hline Latvia & 28.65 & 1.95 & 28378 & Yes \\
\hline Slovenia & 28.62 & 2.07 & 36163 & No \\
\hline Lithuania & 21.83 & 2.85 & 33325 & Yes \\
\hline Albania & 13.32 & 2.87 & 4533 & No \\
\hline Norway & 30.74 & 5.26 & 62182 & Yes \\
\hline Slovakia & 27.96 & 5.44 & 32376 & No \\
\hline Sweden & 28.23 & 10.00 & 51405 & Yes \\
\hline Greece & 16.05 & 10.77 & 28580 & No \\
\hline Netherlands & 29.96 & 17.08 & 54504 & Yes \\
\hline Romania & 14.93 & 19.64 & 10793 & Yes \\
\hline Poland & 23.64 & 37.97 & 29583 & Yes \\
\hline Spain & 23.10 & 46.53 & 39087 & No \\
\hline Italy & 36.34 & 60.59 & 40981 & Yes \\
\hline UK & 25.84 & 65.84 & 44909 & \\
\hline France & 32.80 & 66.80 & 44125 & 34744 \\
\hline Median & 28.09 & 10.38 & & \\
\hline
\end{tabular}

All values for 2017. Conversion rate: $€ 1=$ US $\$ 1.1369$ (mid 2017). VAT included where social security organisations are subject to VAT. Countries in order of population size. Abbreviations: $\mathrm{mn}=$ million; VAT $=$ value added tax 
Figure 4 - Scatter plot of originator fludarabine prices against GDP per capita for 16 European countries where no generic fludarabine existed in 2017

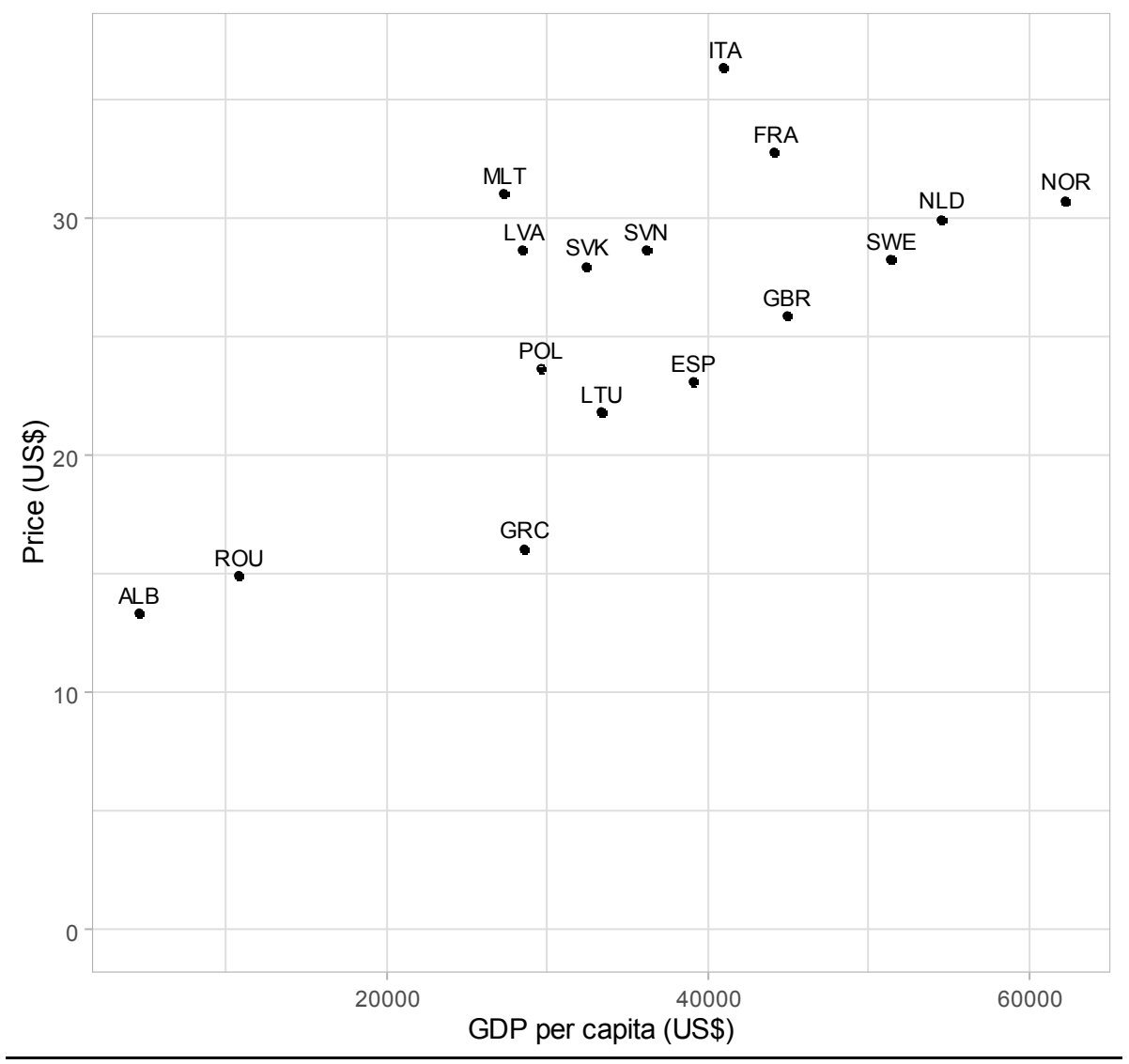

Prices for both erlotinib and fludarabine were relatively stable between 2013 and 2017 among the studied Western European countries (Table 4).

Table 4 - Percentage price changes for originator erlotinib 150mg and fludarabine 10mg in $2017 \mathrm{vs.}$ 2013 among Western European countries

\begin{tabular}{|l|c|c|}
\hline Country & Erlotinib 150mg & Fludarabine 10mg \\
\hline Malta & 0.0 & 0.0 \\
\hline Norway & -12.7 & -16.4 \\
\hline Austria & -10.7 & \\
\hline Sweden & -9.1 & -14.0 \\
\hline Greece & +2.4 & +2.2 \\
\hline Netherlands & -1.9 & -0.6 \\
\hline Spain & 0.0 & -8.1 \\
\hline Italy & -5.0 & 0.0 \\
\hline UK & 0.0 & +11.3 \\
\hline France & -7.1 & -0.5 \\
\hline Germany & 0.0 & \\
\hline
\end{tabular}

NB: Price changes based on initial Euro prices. Countries in order of population size. 


\section{Discussion}

We believe this is the first study to investigate reimbursed prices over time for both patented and generic oral oncology medicines (43) across an appreciable number of European countries to provide future direction. Both studies have shown that prices of oral oncology medicines were not dependent on population sizes despite earlier concerns $(43,92)$, which mirrors findings from other studies $(41$, $94,95)$. However, we are not sure why there were greater price differences than seen in the studies of Vogler et al and Vokinger et al $(40,41)$. This may reflect greater implementation of external reference pricing as well as greater implementation of MEAs which have grown in recent years (51, $62,64)$. However, further research is needed before we can make any definitive statements. A concern though is that the prices of patented oral cancer medicines tended to be higher in countries with greater economic power (Figures 2 to 4 ). These countries may well be able to more aggressively negotiate confidential discounts or rebates as part of MEAs. However, patients in CEE countries that reference these countries for pricing purposes may be faced with higher co-payments, which is an issue that needs addressing. Potential ways forward include greater pricing transparency to justify higher prices in one European country over another coupled the growth in Pan-European purchasing consortia $(96,97)$.

Encouragingly, Godman et al (43) in their earlier study found there were no differences in the pricing approaches for oral oncology multiple sourced medicines as opposed to other disease areas. This is very different to the situation for new oncology medicines where premium prices have been granted for very limited health gain unlike other disease areas $(11,12)$. Encouragingly as well, prices for multiple sourced products were similar across the indications including still patented indications at the multiple source price (43). This was unlike the situation for pregabalin when generic versions were first launched where general practitioners in some countries were threatened with legal action if they prescribed generic pregabalin as opposed to the appreciably more expensive originator for a still patented indication (98). I.

Thirdly, substantial price reductions of up to $98.8 \%$ were seen following the availability of oral generic oncology medicines across Europe (Box 1) (43). These encouraging findings are important to maximise available savings from generic availability to fund increased medicine volumes, as well as new valued high-priced oncology medicines within Europe with its dual aims of universal and equitable access to all for healthcare especially as more standard medicines lose their patent. However, care must be taken that low prices for generic medicines do not lead to shortages and the removal of medicines from the market in this priority disease area $(99,100)$.

We also found limited price erosion for patented oral oncology medicines over time in this study (Table 4) versus the situation seen with oral generic oncology medicines in the earlier study of Godman et al (2019) where increasing competition helped lower prices (43). However, it is likely in the future there will be greater re-evaluation of the prices of existing patented oncology medicines as more oncology medicines used as benchmarks for their pricing and reimbursement negotiations lose their patents $(101,102)$ combined with growing pressures on oncology budgets. Such activities are also likely to grow under value based pricing considerations especially given the level of price reductions that are now being seen for oral generic oncology medicines (up to $97.8 \%$ - Box 1 ), biosimilars (83\% reduction in expenditure on adalimumab among Danish hospitals following biosimilars) and originators with the imminent launch of biosimilars ( $89 \%$ price reduction in the Netherlands for Humira ${ }^{\circledR}$ just before biosimilars were launched) $(35,43,103-105)$. In addition, ongoing measures among European countries to rapidly use new biosimilars for oncology and rheumatoid arthritis to conserve valuable resources without compromising care (106-110). Valuebased pricing (VBP) means 'that countries set prices for new medicines and/or decide on reimbursement based on the therapeutic value which medicine offers, usually assessed through health technology assessment (HTA) or economic evaluation' (25). Consequently under VBP, the prices of patented oncology medicines that used medicines that subsequently became available as either oral generic medicines or biosimilars as their reference for reimbursement purposes should fall following substantial changes in their 'value'. As a result, in the first instance health authorities should seek appreciably greater discounts from companies for continued reimbursement of still patented medicines as part of any existing MEA. Secondly, instigate prescribing restrictions to selected patient groups until there are actual reductions in list prices and/ or discounts $(51,104,111)$. There also needs to be similar considerations for other patented oncology medicines to treat pertinent cancers and stages as the prices and value of oncology medicines targeting the same population change. In 
view of these developments, it is likely that health authorities will increasingly monitor prices and value of oncology medicines and seek redress where these change.

We are aware of a number of limitations with this study discussed in the Methodology section. Despite these limitations, we believe our findings are robust and provide future direction.

\section{Conclusion}

There is a concern that the prices of patented oral cancer medicines tended to be higher in countries with greater economic power, which needs to be addressed going forward. However, of greater concern is that the substantial lowering of prices for generic oral oncology medicines was not universal across Europe. This may start to change as pressures on the oncology medicine budget continue to grow. Of equal concern is a current lack of the re-assessment of the price, value, and place in treatment of patented oncology medicines following the patent loss of the medicines used for pricing and reimbursement negotiations. Such pro-activity is increasingly essential given the likely growth in global expenditure for oncology medicines in the coming years fuelled by rising prevalence rates coupled with the launch of a considerable number of new high-priced oncology medicines. We will continue to monitor any developments given the number of oncology medicines losing their patents in the near future.

\section{Disclaimer and funding}

The majority of the co-authors work for health authorities and health insurance companies across Europe or are advisers to them. Steven Simoens has previously held the EGA Chair "European policy towards generic medicines". All the authors have no other conflicts of interest to declare. The study was self funded.

\section{References}

1. OECD. Health at a Glance 2017. Available at URL: https://www.oecdilibrary.org/docserver/health_glance-2017-

en.pdf?expires=1531413926\&id=id\&accname=guest\&checksum=656327F799B10217DD2D80F463D AB8732017.

2. Luzzatto L, Hyry HI, Schieppati A, Costa E, Simoens S, Schaefer F, et al. Outrageous prices of orphan drugs: a call for collaboration. Lancet. 2018;392(10149):791-4.

3. Prasad V, De Jesus K, Mailankody S. The high price of anticancer drugs: origins, implications, barriers, solutions. Nature reviews Clinical oncology. 2017;14(6):381-90.

4. Gyawali B, Sullivan R. Economics of Cancer Medicines: For Whose Benefit? The New bioethics : a multidisciplinary journal of biotechnology and the body. 2017;23(1):95-104.

5. Kelly RJ, Smith TJ. Delivering maximum clinical benefit at an affordable price: engaging stakeholders in cancer care. The Lancet Oncology. 2014;15(3):e112-8.

6. Howard DH BP, Berndt ER, Conti RM. Pricing in the Market for Anticancer Drugs. Journal of Economic Perspectives. 2015;29(1):139-62.

7. Prasad V, Wang R, Afifi SH, Mailankody S. The Rising Price of Cancer Drugs-A New Old Problem? JAMA oncology. 2017;3(2):277-8.

8. Memorial Sloan Kettering Cancer Centre - Centre for Health Policy and Outcomes. Price \& Value of Cancer Drug. 2020. Available at URL: https://www.mskcc.org/research-programs/healthpolicy-outcomes/cost-drugs.

9. Bach PB, Saltz LB. Raising the Dose and Raising the Cost: The Case of Pembrolizumab in Lung Cancer. Journal of the National Cancer Institute. 2017;109(11).

10. IMS Institute for Healthcare Informatics. Global Oncology Trend Report. A Review of 2015 and Outlook to 2020. June 2016. Available at URL:

https://www.scribd.com/document/323179495/IMSH-Institute-Global-Oncology-Trend-2015-2020Report.

11. Godman B, Bucsics A, Vella Bonanno P, Oortwijn W, Rothe CC, Ferrario A, et al. Barriers for Access to New Medicines: Searching for the Balance Between Rising Costs and Limited Budgets.

Front Public Health. 2018;6:328.

12. Haycox A. Why Cancer? PharmacoEconomics. 2016;34(7):625-7.

13. Godman B, Wild C, Haycox A. Patent expiry and costs for anti-cancer medicines for clinical use. Generics and Biosimilars Initiative Journal 2017;6(3):105-6. 
14. Waters R, Urquhart L. EvaluatePharma $®$ World Preview 2019, Outlook to 2024. 2019. Available at URL: https://info.evaluate.com/rs/607-YGS364/images/EvaluatePharma_World_Preview_2019.pdf.

15. Simoens S, van Harten W, Lopes G, Vulto A, Meier K, Wilking N. What Happens when the Cost of Cancer Care Becomes Unsustainable. European Oncology \& Haematology. 2017;13(2):10813.

16. Wilking N, Lopes G, Meier K, Simoens S, van Harten W, Vulto A. Can we Continue to Afford Access to Cancer Treatment? European Oncology \& Haematology,. 2017;13(2):114-9.

17. Ghinea H, Kerridge I, Lipworth W. If we don't talk about value, cancer drugs will become terminal for health systems. 2015. Available at URL: http://theconversation.com/if-we-dont-talk-aboutvalue-cancer-drugs-will-become-terminal-for-health-systems-44072

18. European Commission. COMMUNICATION FROM THE COMMISSION TO THE EUROPEAN PARLIAMENT, THE COUNCIL, THE EUROPEAN ECONOMIC AND SOCIAL COMMITTEE AND THE COMMITTEE OF THE REGIONS. Pharmaceutical Strategy for Europe - $\{S W D(2020) 286$ final $\}$. Novermber 2020. Available at URL: https://eur-lex.europa.eu/legalcontent/EN/TXT/PDF/?uri=CELEX:52020DC0761\&from=EN.

19. Bentley C, Costa S, Burgess MM, Regier D, McTaggart-Cowan H, Peacock SJ. Trade-offs, fairness, and funding for cancer drugs: key findings from a deliberative public engagement event in British Columbia, Canada. BMC health services research. 2018;18(1):339-.

20. Wild C, Grossmann N, Bonanno PV, Bucsics A, Furst J, Garuoliene K, et al. Utilisation of the ESMO-MCBS in practice of HTA. Annals of oncology. 2016;27(11):2134-6.

21. WHO. Access to new medicines in Europe: technical review of policy initiatives and opportunities for collaboration and research. 2015. Available at URL:

http://www.euro.who.int/_data/assets/pdf_file/0008/306179/Access-new-medicines-TR-PIOcollaboration-research.pdf?ua=1 [

22. WHO. Pricing of cancer medicines and its impacts. Geneva: World Health Organization; 2018. Licence: CC BY-NC-SA 3.0 IGO. Available at URL:

https://apps.who.int/iris/bitstream/handle/10665/277190/9789241515115eng.pdf? sequence $=1$ \&isAllowed $=y$.

23. Grössmann N, Del Paggio JC, Wolf S, Sullivan R, Booth CM, Rosian K, et al. Five years of EMA-approved systemic cancer therapies for solid tumours-a comparison of two thresholds for meaningful clinical benefit. Eur J Cancer. 2017;82:66-71.

24. Cohen D. Cancer drugs: high price, uncertain value. BMJ. 2017;359:j4543.

25. Vogler S. Fair prices for medicines? Exploring competent authorities' and public payers' preferences on pharmaceutical policies. Empirica. 2019;46(3):443-69.

26. Godman B, Campbell S, Suh HS, Finlayson AE, Bennie M, Gustafsson LL. Ongoing Measures to Enhance Prescribing Efficiency Across Europe: Implications for Other Countries. J Health Tech Assess 2013;1(27-42).

27. Suleman F, Low M, Moon S, Morgan SG. New business models for research and development with affordability requirements are needed to achieve fair pricing of medicines. BMJ. 2020;368:|4408-I.

28. AIM. AIM PROPOSES TO ESTABLISH A EUROPEAN DRUG PRICING MODEL FOR FAIR AND TRANSPARENT PRICES FOR ACCESSIBLE PHARMACEUTICAL INNOVATIONS. 2019. Available at URL: https://www.aim-mutual.org/wp-content/uploads/2019/12/AIMs-proposal-for-fairand-transparent-prices-for-pharmaceuticals.pdf.

29. Uyl-de Groot CA, Lowenberg B. Sustainability and affordability of cancer drugs: a novel pricing model. Nature reviews Clinical oncology. 2018;15(7):405-6.

30. Hsu JC, Lin J-Y, Lin P-C, Lee Y-C. Comprehensive value assessment of drugs using a multicriteria decision analysis: An example of targeted therapies for metastatic colorectal cancer treatment. PloS one. 2019;14(12):e0225938-e.

31. Wilking N, Bucsics A, Kandolf Sekulovic L, Kobelt G, Laslop A, Makaroff L, et al. Achieving equal and timely access to innovative anticancer drugs in the European Union (EU): summary of a multidisciplinary CECOG-driven roundtable discussion with a focus on Eastern and South-Eastern EU countries. ESMO open. 2019;4(6):e000550-e.

32. Moon S, Mariat S, Kamae I, Pedersen HB. Defining the concept of fair pricing for medicines. BMJ. 2020;368:I4726-I.

33. WHO. WHO guideline on country pharmaceutical pricing policies, second edition. Geneva: World Health Organization; 2020. Available at URL:

https://apps.who.int/iris/bitstream/handle/10665/335692/9789240011878-eng.pdf. 
34. Hill A, Redd C, Gotham D, Erbacher I, Meldrum J, Harada R. Estimated generic prices of cancer medicines deemed cost-ineffective in England: a cost estimation analysis. BMJ open. 2017;7(1):e011965.

35. Sagonowsky E. AbbVie's massive Humira discounts are stifling Netherlands biosimilars: report. 2019. Available at URL: https://www.fiercepharma.com/pharma/abbvie-stifling-humira-biosimcompetition-massive-discounting-dutch-report.

36. Tefferi A, Kantarjian H, Rajkumar SV, Baker LH, Abkowitz JL, Adamson JW, et al. In Support of a Patient-Driven Initiative and Petition to Lower the High Price of Cancer Drugs. Mayo Clin Proc. 2015;90(8):996-1000.

37. DeMartino PC, Miljkovic MD, Prasad V. Potential Cost Implications for All US Food and Drug Administration Oncology Drug Approvals in 2018. JAMA Intern Med. 2020.

38. Vogler S, Schneider P, Zimmermann N. Evolution of Average European Medicine Prices: Implications for the Methodology of External Price Referencing. PharmacoEconomics - open. 2019;3(3):303-9.

39. Emanuel EJ, Zhang C, Glickman A, Gudbranson E, DiMagno SSP, Urwin JW. Drug Reimbursement Regulation in 6 Peer Countries. JAMA Intern Med. 2020.

40. Vogler S, Zimmermann N, Babar ZU. Price comparison of high-cost originator medicines in European countries. Expert review of pharmacoeconomics \& outcomes research. 2017;17(2):221-30. 41. Vokinger KN, Hwang TJ, Grischott T, Reichert S, Tibau A, Rosemann T, et al. Prices and clinical benefit of cancer drugs in the USA and Europe: a cost-benefit analysis. The Lancet Oncology. 2020;21(5):664-70.

42. Leopold C, Vogler S, Mantel-Teeuwisse AK, de Joncheere K, Leufkens HG, Laing R. Differences in external price referencing in Europe: a descriptive overview. Health policy. 2012;104(1):50-60.

43. Godman B, Hill A, Simoens S, Kurdi A, Gulbinovič J, Martin AP et al. Pricing of oral generic cancer medicines in 25 European countries; findings and implications. Generics and Biosimilars Initiative Journal (GaBI Journal). 2019;8(2):49-70.

44. Eatwell E, Swierczyna A. Emerging voluntary cooperation between European healthcare systems: Are we facing a new future?. Medicine Access@Point of Care 2019; 1-8.

45. O'Mahony JF. Beneluxa: What are the Prospects for Collective Bargaining on Pharmaceutical Prices Given Diverse Health Technology Assessment Processes? PharmacoEconomics. 2019;37(5):627-30.

46. European Commission. DEFINING VALUE IN “VALUE BASED HEALTHCARE”. Report of the Expert Panel on effective ways of investing in Health (EXPH). 2019. Available at URL: https://ec.europa.eu/health/sites/health/files/expert_panel/docs/024_defining-value-vbhc_en.pdf. 47. Godman B, Wettermark B, van Woerkom M, Fraeyman J, Alvarez-Madrazo S, Berg C, et al. Multiple policies to enhance prescribing efficiency for established medicines in Europe with a particular focus on demand-side measures: findings and future implications. Frontiers in pharmacology. 2014;5:106.

48. Moorkens E, Vulto AG, Huys I, Dylst P, Godman B, Keuerleber S, et al. Policies for biosimilar uptake in Europe: An overview. PloS one. 2017;12(12):e0190147.

49. Godman B, Malmstrom RE, Diogene E, Jayathissa S, McTaggart S, Cars T, et al. Dabigatran - a continuing exemplar case history demonstrating the need for comprehensive models to optimize the utilization of new drugs. Frontiers in pharmacology. 2014;5:109.

50. Vogler S. The impact of pharmaceutical pricing and reimbursement policies on generics uptake: implementation of policy options on generics in 29 European countries-an overview. Generics and Biosimilar Journal. 2012;1(2):93-100.

51. Ferrario A, Arāja D, Bochenek T, Čatić T, Dankó D, Dimitrova M, et al. The Implementation of Managed Entry Agreements in Central and Eastern Europe: Findings and Implications.

PharmacoEconomics. 2017;35(12):1271-85.

52. Vella Bonanno P, Bucsics A, Simoens S, Martin AP, Oortwijn W, Gulbinovic J, et al. Proposal for a regulation on health technology assessment in Europe - opinions of policy makers, payers and academics from the field of HTA. Expert review of pharmacoeconomics \& outcomes research. 2019;19(3):251-61.

53. Godman B, Shrank W, Andersen M, Berg C, Bishop I, Burkhardt T, et al. Policies to enhance prescribing efficiency in europe: findings and future implications. Frontiers in pharmacology. 2010;1:141.

54. Moon JC, Godman B, Petzold M, Alvarez-Madrazo S, Bennett K, Bishop I, et al. Different initiatives across Europe to enhance losartan utilization post generics: impact and implications. Frontiers in pharmacology. 2014;5:219. 
55. Voncina L, Strizrep T, Godman B, Bennie M, Bishop I, Campbell S, et al. Influence of demand-side measures to enhance renin-angiotensin prescribing efficiency in Europe: implications for the future. Expert review of pharmacoeconomics \& outcomes research. 2011;11(4):469-79.

56. Vogler S, Schneider P. Assessing Data Sources for Medicine Price Studies. International journal of technology assessment in health care. 2019;35(2):106-15.

57. Godman B, Petzold M, Bennett K, Bennie M, Bucsics A, Finlayson AE, et al. Can authorities appreciably enhance the prescribing of oral generic risperidone to conserve resources? Findings from across Europe and their implications. BMC medicine. 2014;12:98.

58. Godman B, Shrank W, Andersen M, Berg C, Bishop I, Burkhardt T, et al. Comparing policies to enhance prescribing efficiency in Europe through increasing generic utilization: changes seen and global implications. Expert review of pharmacoeconomics \& outcomes research. 2010;10(6):707-22.

59. Godman B, Bishop I, Finlayson AE, Campbell S, Kwon HY, Bennie M. Reforms and initiatives in Scotland in recent years to encourage the prescribing of generic drugs, their influence and implications for other countries. Expert review of pharmacoeconomics \& outcomes research. 2013;13(4):469-82.

60. WHO. WHO Collaborating Centre for Drug Statistics Methodology. ATC/ DDD Index. 2019. Available at URL: https://www.whocc.no/

61. Adamski J, Godman B, Ofierska-Sujkowska G, Osinska B, Herholz H, Wendykowska K, et al. Risk sharing arrangements for pharmaceuticals: potential considerations and recommendations for European payers. BMC health services research. 2010;10:153.

62. Zampirolli Dias C, Godman B, Gargano LP, Azevedo PS, Garcia MM, Souza Cazarim M, et al. Integrative Review of Managed Entry Agreements: Chances and Limitations.

PharmacoEconomics. 2020;38(11):1165-85.

63. Pauwels K, Huys I, Vogler S, Casteels M, Simoens S. Managed Entry Agreements for Oncology Drugs: Lessons from the European Experience to Inform the Future. Frontiers in pharmacology. 2017;8:171.

64. Darbà J, Ascanio M. The current performance-linked and risk sharing agreement scene in the Spanish region of Catalonia. Expert review of pharmacoeconomics \& outcomes research. 2019;19(6):743-8.

65. British Pound to Euro Spot Exchange Rates for 2013 from the Bank of England. Available at URL: https://www.poundsterlinglive.com/bank-of-england-spot/historical-spot-exchangerates/gbp/GBP-to-EUR-2013.

66. British Pound to Euro Spot Exchange Rates for 2014 from the Bank of England. Available at URL: https://www.poundsterlinglive.com/bank-of-england-spot/historical-spot-exchangerates/gbp/GBP-to-EUR-2014.

67. British Pound to Euro Spot Exchange Rates for 2015 from the Bank of England. Available at URL: https://www.poundsterlinglive.com/bank-of-england-spot/historical-spot-exchangerates/gbp/GBP-to-EUR-2015.

68. SVERIGES RIKSBANK Exchange Rates. Available at URL: https://www.riksbank.se/engb/statistics/search-interest--exchange-rates/?g130-

SEKEURPMI=on\&from $=28 \% 2 F 12 \% 2 F 2017 \&$ to $=29 \% 2 F 12 \% 2 F 2017 \& \mathrm{f}=$ Day\&c=cAverage $\& \mathrm{~s}=$ Comma . 69. Narodowy Bank Polski - Exchange Rates. Available at URL:

http://www.nbp.pl/homen.aspx?f=/kursy/kursyen.htm.

70. National Bank of Serbia - Exchange Rate. Available at URL:

https://www.nbs.rs/export/sites/default/internet/english/scripts/kl_srednji.html.

71. Norges Bank Exchange Rates. Available at URL: https://www.norges-

bank.no/en/topics/Statistics/exchange_rates/.

72. Banca Naţională a României - Exchange rates. Available at URL:

https://www.bnr.ro/Exchange-Rates--3727.aspx.

73. OECD Stat. Level of GDP per capita and productivity 20187 Available at URL:

https://stats.oecd.org/Index.aspx?DataSetCode=PDB_LV.

74. European Central Bank. Euro Foreign Exchange Reference Rates. 1 July 2015. Available at URL: https://www.ecb.europa.eu/stats/exchange/eurofxref/shared/pdf/2015/07/20150701. pdf.

75. European Central Bank. Euro Foreign Exchange Reference Rates. 3 July 2017. Available at URL: https://www.ecb.europa.eu/stats/exchange/eurofxref/shared/pdf/2017/07/20170703.pdf.

76. Trading Economics - Albania GDP per capita 2017, 2018. Available at URL:

https://tradingeconomics.com/albania/gdp-per-capita.

77. OECD Data. Gross domestic product (GDP) 2018. Available at URL:

https://data.oecd.org/gdp/gross-domestic-product-gdp.htm. 
78. Trading Economics. Serbia GDP per capita. 2017. Available at URL:

https://tradingeconomics.com/serbia/gdp-per-capita.

79. Country Economy. Romania GDP. 2017. Available at URL:

https://countryeconomy.com/gdp/romania.

80. OECD Stat. Population data - 2017. Available at URL:

https://stats.oecd.org/Index.aspx?DataSetCode=EDU_DEM.

81. Republic of Cyprus DEMOGRAPHIC REPORT 2017. Available at URL:

https://www.mof.gov.cy/mof/cystat/statistics.nsf/All/6C25304C1E70C304C2257833003432B3/\$file/DE MOGRAPHIC_REPORT-2017-301118.pdf?OpenElement.

82. Institute of Statistics. Population of Albania, 1 January 2017. Available at URL:

http://www.instat.gov.al/en/themes/demography-and-social-

indicators/population/publication/2017/population-of-albania-1-januar-2017/.

83. World Population Data - Malta. Available at URL:

http://worldpopulationreview.com/countries/malta-population/.

84. Zamfir R. Romania is losing its people! Over 0.6 percent of the population vanished in just

one year. Business Review 2018. Available at URL: http://business-review.eu/news/romania-lost-

120000-people-between-january-2017-and-january-2018-182450.

85. Statistical Office of the Republic of Serbia - Estimates of population of the Republic of Serbia

by sex, age and type of settlement 2013-2017. 2019. Available at URL:

http://publikacije.stat.gov.rs/G2018/PdfE/G201815012.pdf.

86. World Bank - Kosovo. 2019. Available at URL: https://data.worldbank.org/country/kosovo.

87. International Organization for Standardization (ISO). ISO 3166 Country Codes Alpha-3. 2013.

Available at URL: https://www.iso.org/obp/ui.

88. R Core Team. R: A language and environment for statistical computing. R Foundation for Statistical Computing, Vienna, Austria. 2019. Available at URL: https://www.R-project.org/.

89. Godman B, Kurdi A, McCabe H, Johnson CF, Barbui C, MacBride-Stewart S, et al. Ongoing initiatives within the Scottish National Health Service to affect the prescribing of selective serotonin reuptake inhibitors and their influence. Journal of comparative effectiveness research. 2019;8(7):53547.

90. Simoens S. A reviewof generic medicine pricing in Europe. Generics and Biosimilar Journal. 2012;1(1):8-12.

91. Godman B, Wettermark B, Bishop I, Burkhardt T, Fürst J, Garuoliene K, et al. European payer initiatives to reduce prescribing costs through use of generics2012. 22-7 p.

92. McKee M, Stuckler D, Martin-Moreno JM. Protecting health in hard times. BMJ.

2010;341:c5308.

93. Godman B, Acurcio F, Guerra Junior AA, Alvarez-Madrazo S, Faridah Aryani MY et al. Initiatives among authorities to improve the quality and efficiency of prescribing and the implications. $J$ Pharma Care Health Sys. 2014;1(3):1-15.

94. Markovic-Pekovic V, Skrbic R, Godman B, Gustafsson LL. Ongoing initiatives in the Republic of Srpska to enhance prescribing efficiency: influence and future directions. Expert review of pharmacoeconomics \& outcomes research. 2012;12(5):661-71.

95. Garuoliene K, Godman B, Gulbinovic J, Wettermark B, Haycox A. European countries with small populations can obtain low prices for drugs: Lithuania as a case history. Expert review of pharmacoeconomics \& outcomes research. 2011;11(3):343-9.

96. Office of the Deputy Prime Minister and the Ministry for Health of Malta. Valletta Technical Group continues to grow. 2018. Available at URL:

http://www.livenewsmalta.com/index.php/2018/01/31/valletta-technical-group-continues-to-grow/ 97. O'Mahony JF. Beneluxa: What are the Prospects for Collective Bargaining on Pharmaceutical Prices Given Diverse Health Technology Assessment Processes? PharmacoEconomics. 2019;37(5):627-30.

98. Godman B, Wilcock M, Martin A, Bryson S, Baumgärtel C, Bochenek T, de Bruyn M. Generic pregabalin; current situation and implications for health authorities, generics and biosimilars manufacturers in the future. GaBI Journal. 2015;4(3):125-35.

99. Dylst P, Vulto A, Godman B, Simoens S. Generic medicines: solutions for a sustainable drug market? Applied health economics and health policy. 2013;11(5):437-43.

100. Bochenek T, Abilova V, Alkan A, Asanin B, de Miguel Beriain I, Besovic Z, et al. Systemic Measures and Legislative and Organizational Frameworks Aimed at Preventing or Mitigating Drug Shortages in 28 European and Western Asian Countries. Frontiers in pharmacology. 2017;8:942. 101. Huang HY, Wu DW, Ma F, Liu ZL, Shi JF, Chen X, et al. Availability of anticancer biosimilars in 40 countries. The Lancet Oncology. 2020;21(2):197-201. 
102. Derbyshire M, Shina S. Patent expiry dates for biologicals: 2017 update. Generics and Biosimilars Initiative Journal (GaBI Journal). 2018;7(1):29-34.

103. Godman B, Allocati E, Moorkens E. Ever-Evolving landscape of biosimilars in Canada; findings and implications from a global perspective. Generics and Biosimilars Initiatives (GABI) Journal. 2019; 8 (3).

104. Hollis A. Sustainable Financing of Innovative Therapies: A Review of Approaches. PharmacoEconomics. 2016;34(10):971-80.

105. Jensen TB, Kim SC, Jimenez-Solem E, Bartels D, Christensen HR, Andersen JT. Shift From Adalimumab Originator to Biosimilars in Denmark. JAMA Internal Medicine. 2020;180(6):902-3.

106. Godman B. Biosimilars are becoming indispensable in the management of multiple diseases although concerns still exist. Bangladesh Journal of Medical Science. 2021; 20 (1). DOI:

http://dx.doi.org/.

107. Godman B, Allocati E, Moorkens E, Kwon H-Y. Can local policies on biosimilars optimize the use of freed resources - experiences from Italy. Generics and Biosimilars Initiative Journal (GABI). 2020; 9 (4). Available as URL: http://gabi-journal.net/can-local-policies-on-biosimilars-optimize-theuse-of-freed-resources-experiences-from-italy.html.

108. Moorkens M, Godman B, Huys I, Hoxha I, Malaj A, Keuerleber S et al. The expiry of Humira (B) market exclusivity and the entry of adalimumab biosimilars in Europe: An overview of pricing and national policy measures. Front. Pharmacol. 2020 (Accepted for publication doi:

10.3389/fphar.2020.591134).

109. NHS Scotland. Secondary Care National Therapeutic Indicators 2019/20. 2019. Avai;able at URL: https://www.therapeutics.scot.nhs.uk/wp-content/uploads/2020/10/Secondary-care-NTIs-201920-final.pdf.

110. Lee SM, Jung JH, Suh D, Jung YS, Yoo SL, Kim DW, et al. Budget Impact of Switching to Biosimilar Trastuzumab (CT-P6) for the Treatment of Breast Cancer and Gastric Cancer in 28 European Countries. BioDrugs. 2019;33(4):423-36.

111. Matusewicz W, Godman B, Pedersen HB, Furst J, Gulbinovic J, Mack A, et al. Improving the managed introduction of new medicines: sharing experiences to aid authorities across Europe. Expert review of pharmacoeconomics \& outcomes research. 2015;15(5):755-8. 


\section{Appendix}

\section{Tables}

Table 1A - ISO 3166 Country Codes (Alpha-3)

\begin{tabular}{l|c|} 
Country & Country Code \\
\hline Albania & ALB \\
\hline Austria & AUT \\
\hline Belgium & BEL \\
\hline Cyprus & CYP \\
\hline France & FRA \\
\hline Germany & DEU \\
\hline Greece & GRC \\
\hline Italy & ITA \\
\hline Kosovo & XKX \\
\hline Latvia & LVA \\
\hline Lithuania & LTU \\
\hline Malta & MLT \\
\hline Netherlands & NLD \\
\hline Norway & NOR \\
\hline Poland & POL \\
\hline Romania & ROU \\
\hline Serbia & SRB \\
\hline Slovakia & SVK \\
\hline Slovenia & SVN \\
\hline Spain & ESP \\
\hline Sweden & SWE \\
\hline United Kingdom & GBR \\
\hline
\end{tabular}




\section{Figures}

Figure $1 \mathrm{~A}-$ Scatter plot of originator imatinib prices against population size for 11 European countries where no generic imatinib existed in 2015

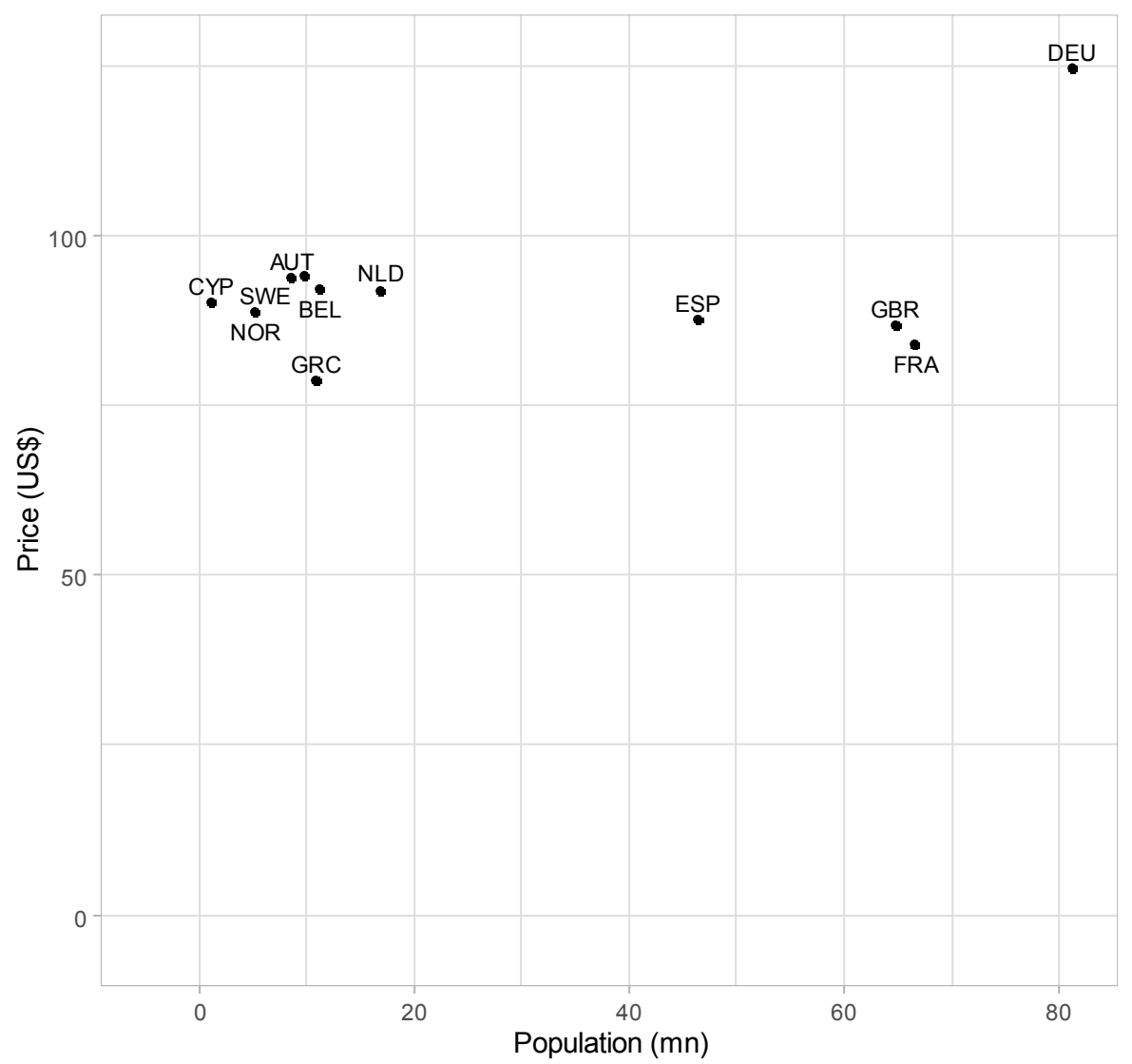


Figure 2A - Scatter plot of originator erlotinib prices against population size for 16 European countries where no generic erlotinib existed in 2017

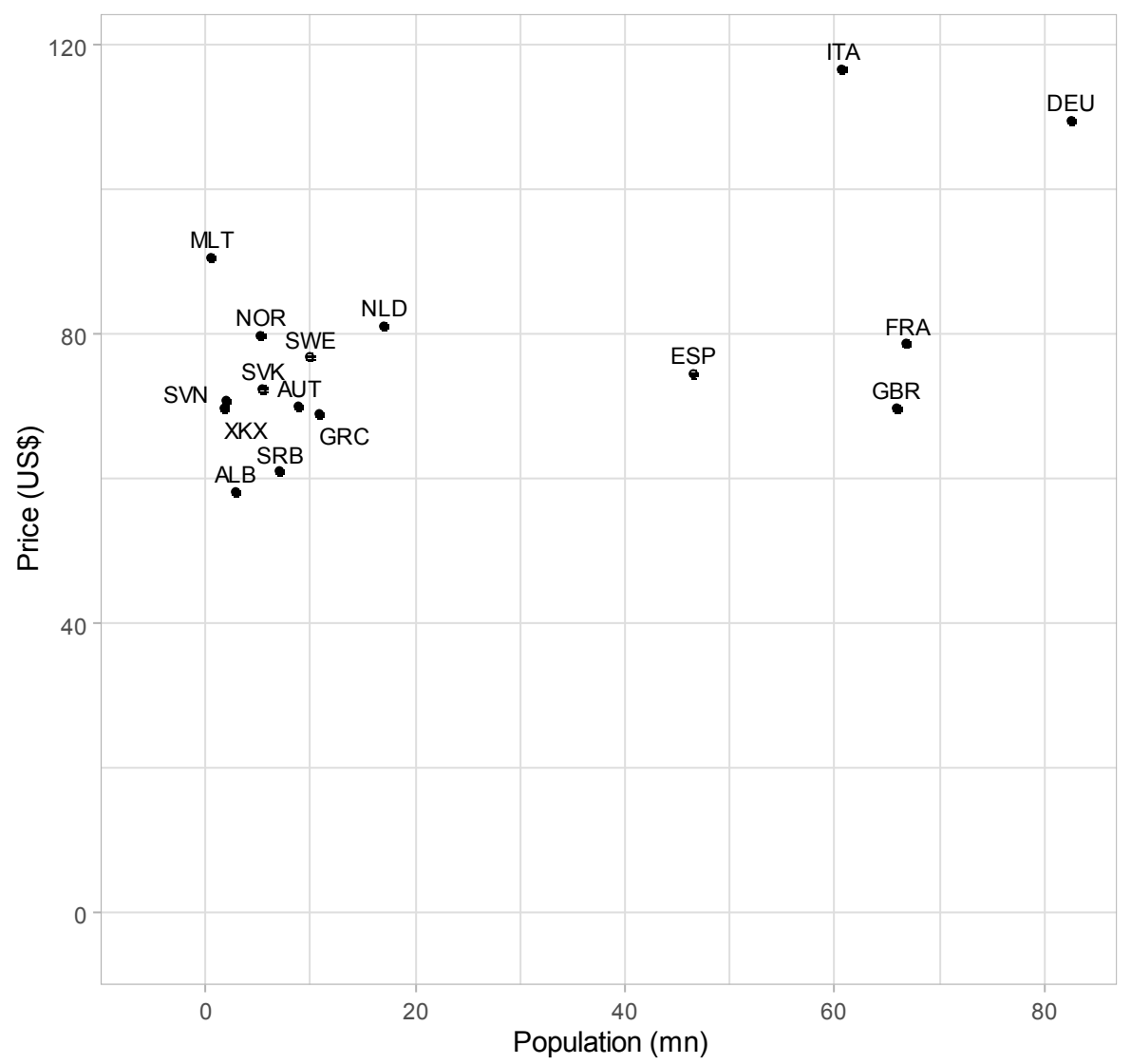


Figure $3 \mathrm{~A}$ - Scatter plot of originator fludarabine prices against population size for 16 European countries where no generic fludarabine existed in 2017

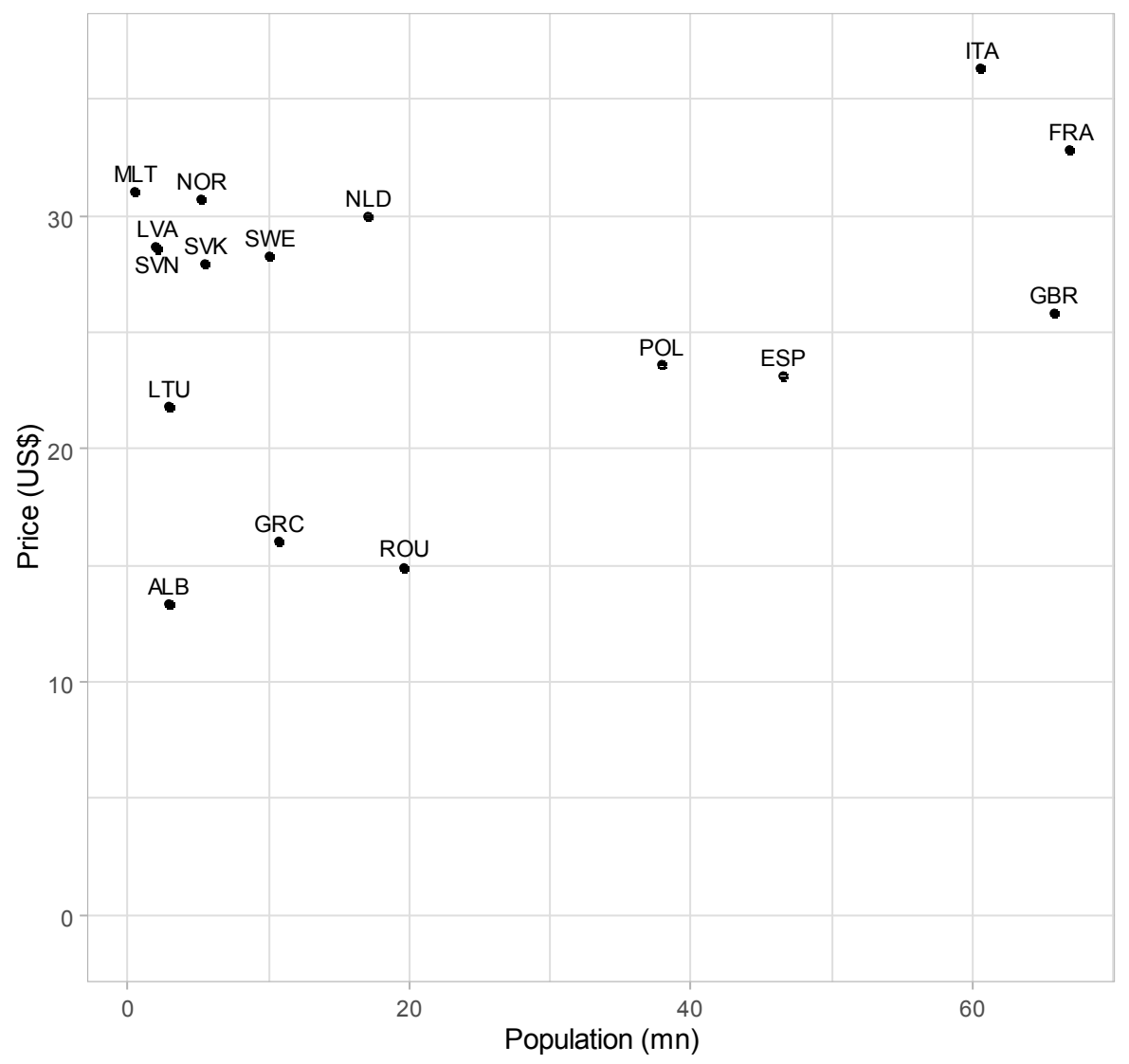

